Ricardo Donoso

\title{
La leyenda de las joyas de la reina Isabel
}

Lo que dicen los fextos de Barros Arana, Gaspar Toro y Galdames.-Los principales culpables: lrving y Prescott.-Origen de la leyendo: testimonio de don Fernando Colón.-El padre Las Casas. Herrera. López de Gómara y Muñoz difunden la conseja.-Cronistas e historiadores que no la consignan.-La labor critica: Fernández Duro, Ibarra y Rodriguez, y Serrano y Sanz.-El Libro Verde de Aragón y sus revelaciones.-Luis de Santangel y su ascendencia judaica.-Sus relaciones con Colón.-Procedencia del dinero con que se afendió a los gastos de la expedición descubridora.La acción de la reina.

ESDE hace buen número de años la crilica moderna ha desechado la socorrida leyenda del empeño de las joyas de la reina Isabel de Castilla para sufragar los gastos que demandara la expedición descubridora del genial genovés, a pesar de lo cual todavía se repite en la cátedra y en los libros de texto. Es verdad que ella ha sido difundida por autores de tan indisculible auloridad como don Diego Barros Arana, quien en su Compendio de historia de América, dado a la eslampa en 1865, escribia: Entonces perdió Colón todas sus esperanzas y no pensó más que en pasar a Francia. Parecia que un poder misterioso contrariaba su suerte en los momentos en que 
se creia próximo a recoger el fruto de tantas fatigas. afanes y contradicciones. A principios de Febrero de 1492, Colón partió de Santa Fe: pero al saber esta noticia, las pocas personas que se habian inleresado por él y por sus proyectos, resolvieron impedir su marcha. Luis de Santangel. receptor de las rentas eclesiásticas de Aragón, y Alonso de Quintanilla, se presentaron a la reina. El peligro que corría la grande empresa del marino genovés les dió audacia y elocuencia. No se limitaron a súplicas, sino que llegaron a reconvenir a la reina por la terquedad con que sus comisarios se habian negado a conceder a Colón lo que pedía. La grande alma de Isabel se sintió conmovida: y como el rey vacilara ante la idea de los gastos que la empresa iba a originar, su esposa exclamó: Yo la acepto por la corona de Castilla, aún cuando fuese necesario empeñar mis joyas para sufragar sus gastos». Inmedialamente partió un correo en busca de Colón, que se hallaba ya a diez leguas de Granada. La reina lo recibió con una generosa bondad, capaz de hacerle olvidar sus pasados dolores, y ordenó que su secretario Juan de Coloma, extendiese las capitulaciones, ?

Idéntica afirmación se encuentra en el lexto de don Gaspar Toro, aprobado por la Universidad de Chile para el uso de los establecimientos de segunda enseñanza, donde se lee: ¿El prior de la Rábida lo detuvo. Los reyes tomaron a Granada, y ya fué más fácil a Colón mover en su favor el ánimo de Isabel. Se cuenta que, cuando ésta vió a su marido vacilante por los gastos de la empresa, exclamó: Yo lo acepto por la corona de Castilla, aún cuando sea necesario empeñar mis joyas para costear sus gastos, *.

Aún más: don Luis Galdames, catedrático distinguidísimo y autor de un muy meritorio Estudio de la historia de Chile, que se usa como texto en nuestros liceos. afirma: Sin embargo. cuando Granada fué tomada por los españoles y la guerra quedó con esto concluida. Isabel de Castilla aceptó las proposiciones

- Pág. 87 de la edición de 1865.

* Compendio de Historia de América y especialmente de Chile, pág. 14 de la edición de 1910 . 


\section{La leyenda de las joyas de la reina Isabel}

de Colón y le prestó recursos para armar tres embarcacioness ".

Nada tiene de extraño que esta leyenda, realmente hermosa. se haya ido repitiendo de siglo en siglo y de generación en generación, pero sí sorprende que un colombista tan sólido y bien enterado como don Enrique Sanfuentes Correa no hubicra esclarecido definitivamente el asunto, del cual sólo tuvo funda. das sospechas, en su notable libro. Tendriamos entonces, es. cribe alli, que todo el dinero para el descubrimiento habria sido proporcionado por genoveses, excepto en la parte de responsabilidad que cabria a Santangel, y que aquello del empeño de las joyas de Isabel la Católica, que hasta lágrimas arrancara a algún poeta, no sería sino la más audaz de las mistificaciones históricas, repetida y glorificada durante cuatro siglos, "

A decir verdad, las escritores nombrados sólo se han limilado a reproducir lo que eminente historiadores han consignado sobre la materia, comenzando por Irving y por Prescolt. No resisto a la tentación de reproducir el párrafo correspondiente de la Historia de la vida y viajes de Cristóbal Colón. por cuanto Irving es uno de los autores que más ha contribuido a la difusión de la leyenda. Todavía tuvo un momento de duda. escribe. El rey miraba con frialdad aquella negociación, y el tesoro real estaba absolutamente agotado por la guerra. Se necesitaba tiempo para llenarlo. ¿Cómo podia la reina girar sobre una caja vacia para medidas a que su esposo se manilestaba adverso? Santangel observaba esta suspensión con trémula ansiedad. Pero no le duró más que un momento Con entusiasmo digno de ella misma y de la causa que patrocinaba, exclamó Isabel: Yo entro en la empresa por mi corona de Castilla, y empeñaré mis joyas para levantar los fondos necesarios. Este fué el noble momento

- Págs. 24-25 de la edición de 1925.

* Cristóbal Colón y su detractor el marqués de Dos Fuentes. Santiago. 1918. pág. 80. 
de la vida de Isabel: por él durará siempre su nombre, como patrona del descubrimiento del Nuevo Mundo."

Prescolt da la misma versión. con las textuales palabras que transcribe Barros Arana. El eminente historiador norleamericano funda su afirmación en el testimonio de Herrera, don Juan Bautisla Muñoz, don Fernando Colón y López de Gómara ** Propiciada por tales autoridades la tradición se difundió y dió amplio tema a escritores y poefas.

Como apunta Henry Vignaud, el origen de la leyenda se remonta al testimonio de don Fernando Colón, cuyo libro vió la luz en Venecia en 1571. Dice el hijo del Almirante: -Visto por Santangel el favor que le hacia la Reina en aceptar lo que por consejo de tantos había desestimado, la respondió que no era necesario empeñar sus joyas. que él serviria a su alteza prestándola el dinero, *

El escrilo del hijo del Almirante no ha visto hasta hoy la luz de la publicidad, y lo que de él se conoce es la traducción que Alonso de Ulloa dió a la estampa en Venecia en el año indicado. El padre Las Casas, que fué uno de sus lectores, dejó inédita su obra durante siglos, y hasta que Herrera y otros historiadores no conocieron su libro, el generoso desprendimiento de la reina no tuvo encomiadores. Pero, como anota Fernández Duro, al tiempo de las laboriosas gestiones de Colón ante la corle, don Fernando era un niño y se hallaba lejos del lugar. De haber sabido la ocurrencia por confidencia de tercera persona, ¿cómo es que ella escapó del conocimiento de los cronistas y escritores contemporáneos, ninguno de los cuales la consigna? El diálogo que don Fernando Colón pone en labios de la reina y de Santangel. que sin faltar a la verdad en lo esen-

- Págs. 36-37 de la edición de Santiego de 1851.

* Historia del reinado de Fernando e Isabel, II. pág. 127.

** 1, pág. 72, edición de Madrid de 1892. Es sabido que la autenticidad del libro de don Fernando Colón ha sido negada por Harrise, don Fernando Colón. historiador de su padre. Sevilla, 1871, volumen del cual hay una edición francesa. más amplia. del año siguiente; y defendida por d'Avezac. Con esfe motivo se planteó una notable polémica; en la que parficipó el eminente americanista con su mordacidad de costumbre, el análisis de la cual nos haria extendernos demasiado. 
cial, relativo al préstamo. está adornado con frases muy del gusto de la época, pone de manifiesto la influencia de los ciásicos latinos, a cuya lectura era muy aficionado el famoso bibliófilo sevillano.

El padre Las Casas, amigo que fué de Colón, cuyo diario de navegación del primer viaje tuvo a la vista. escribe: .Cognosciendo, pues, la Reina católica la istinción y buen celo que tenia Luis de Santangel a su servicio. dijo que le agradecia mucho su deseo y el parecer que le daba y que tenia por bien de seguirlo, pero que se difiriese por entonces hasla que tuviese un poco de quietud y descanso, porque ya veía cuán necesitados estaban con aquellas guerras que tan prolijas habian sido: pero si todavia os parece. Santangel, dice la Reina. que ese hombre ya no podrá sufrir tanta tardanza. yo terné por bien que sobre joyas de mi recámara se busquen prestados los dineros que para hacer el armada pide, y váyase luego a entender en ellas"

El tercer autor que menciona el hecho es Antonio de Herrera. famoso cronista de las Indias. cuya Hisloria general de los hechos de los castellanos en las Islas y Tierra Firme del mar Océano vió la luz en 1601, quien escribe: ¿La Reina, porque se veia importunar en la misma conformidad de Alonso de Quintanilia. que con ella tenía autoridad, los agradeció el Consejo, y dijo que le aceptaba, con que se aguardase a que se alentase algo de los gastós de la Guerra; y que si todavía parecía que se efecfuase luego, tenía por bien. que sobre algunas Joyas de su Cámara, se buscase prestado el dinero que fuese menester. Quintanilla, y Sant-Angel la besaron las manos. porque por consejo suyo hubiese delerminado de hacer. lo que por el de tantos habia rehusado: y Luis de Sant-Angel ofreció de prestar de su hacienda la cantidad necesaria; y con esta resolución mandó la Reina, que fuese un alguacil de la Corte, por la posta. tras don Cristóbal Colón...

Los otros autores cuya autoridad invoca Prescott son López

- Historia de las Indias, I, págs, 247-248.

- Década primera. libro 1.0, cáp. 8. 
de Gómara y el eminente don Juan Bautista Muñoz. De ellos. Gómara, cuya obra vió la luz en Zaragoza en 1553, no repile la tradición, no asi Muñoz. quien la acoge con la mejor buena fe. Inflámase la reyna, dice, dales gracia por el consejo. y acepta la empresa por su corona de Castilla. Bien que añadió, seria menester diferir algun tanto la ejecucion, mientras se rehacia de los gastos de la guerra: mas aún si esta dilación les descontentaba, que alli estaban las joyas de su cámara. y sobre ellas se tomase la cantidad necesaria para el armamento. Lleno de júbilo Sant-Angel ofreció prestar lo suficiente para disponer la expedición sin pérdida de tiempos".

Aún cuando no faltan en los autores citados las referencias a la procedencia del dinero con que se hizo el primer viaje de Colón, la leyenda se propagó y pasó a la posieridad con todos los contornos de un hecho inamovible.

pero ya los contemporáneos habian aludido a ello. Gonzalo Fernández de Oviedo, primer cronisla oficial de las Indias, que fué testigo de casi todos los hechos que relata. afirma: eY porque habia necesidad de dineros para su expedición, a causa de la guerra, los prestó para facer esta primera armada de las Indias y su descubrimiento. el escribano de racion, Luis de SanctAngel, "*.

A su vez Gómara, cuyo lestimonio hay que acoger con reservas, y de quien Muñoz decia que habia dado crédito a patrañas no sólo falsas sino que inverosímiles, escribia: ‘Y porque los Reies no tenian dinero para despachar a Colón. les prestó Luis de S. Angel, su Escribano de Racion, seis cuentos de maravedis, que son en cuenta mas gruesa diez y seis mil ducados,

Los mismos historiadores norteamericanos. Irving y Prescott. admiten que Santangel adelantó las sumas necesarias para el primer inolvidable glorioso viaje del genovés. Es oportuno recordar también, como apunta Vignaud, que ni Fernando del Pulgar. Bernaldez, Nebrija, Oviedo. Pedro Mártir de Angleria. Ge-

- Hisforia del Nuevo Mundo. Libro II. pág. 65.

* Historia General de las Indias, I. pág. 20. 
raldini, Garibay. Mariana y Zurita, conocieron la proposición de la reina que dió origen a la leyenda. Y su testimonio tenía la más decisiva importancia, por tratarse nada menos que de cronistas e hisloriadores contemporáneos, en su mayor parte.

\section{III}

Fué el primero en llamar la atención hacia la falla de fundamento histórico de la socorrida conseja, el distinguido historiador peninsular don Cesáreo Fernández Duro, autor de tantas interesantes páginas sobre Colón, quien, en un estudio que publicó primero en la Revisfa Contemporánea, y recogió después en su libro Tradiciones infundadas, se pronunció resueltamente contra ella. Bien son menester circunspección y pulso, escribe. tratando de investigar los fundamentos de creencia tan arraigada y general, teniendo por sentencia que por increibles que parezcan las hablillas tradicionales, conviene no despreciarlas por completo y profundizar hondamente su examen: sin embargo, con poco que se ejercite la diligencia. no es dificil advertir en principio que la nolicia de haber empeñado la Reina doña Isabel las joyas de la corona. presintiendo el hallazgo de otra que ningún soberano del mundo pudiera ostentar, no procede de aserción nacida en los dias de la ocurrencia, comunicada por personas de la corte que presenciaran el acto o lo supieran. y pasada de boca en boca a las generaciones sucesivas; porque ni los cronistas de la época la consignan, ni los abundantes cancioneros que subsisten de entonces la apuntan, ni en los elogios. biografias, relaciones y epistolarios de los personajes más allegados a los Reyes o que directamente intervinieron en las pretensiones de Cristóbal Colón y en la expedición de las naves que hallaron el Nuevo Mundo se menciona, encontrándose en cualquiera de estos escritos anotación de acaecimientos, de ocurrencias personales, de hechos y dichos de menor significacion. y habiéndolos especiales en que escritores cortesanos, como eran Hernando del Pulgar y Gonzalo Fernández de Oviedo. expresa- 
mente recogian en la Cámara real frases agudas o sentenciosas. anécdolas interesantes y rasgos que sirvieran al retrato moral y físico de los más ilustres de sus coetáneos presentes en la corte de doña Isabel y D. Fernando.

¿No hablando del empeño de las joyas estos cronistas, agrega. ni otros tan bien informados como Pedro Mártir. Andrés Bernáldez. Antonio de Nebrija. Alonso de Santa Cruz. Alvaro Flores, Estanques. Jerónimo de Zurita, sin contar a los biógralos de Quintanilla, el Cardenal Mendoza, el Almirante de Castilla, Deza, Fonseca, Cabrero y el mismo Colón, sin temeridad cabe pensar que no es de aquellos asuntos de origen seguro que en el trascurso del tiempo y por los medios diversos de comunicación se abultan tal vez o desfiguran, pero conservan siempre un fondo de veracidad indisculible: que no es tradición tal, que arranque del momento en que se cree nacida,

Señala en seguida Fernández Duro el origen de la leyenda. cual era la afirmación hecha por el hijo del Almirante de las Indias. don Fernando Colón. la autenticidad de cuya obra ha dado origen a tan ardientes controversias. y cuyo testimonio es de muy discutible autoridad: y observa que fué a principios del siglo XVII cuando los historiadores y cronistas, sin verificar la especie ni registrar los papeles de. Colón. no titubearon en dar por cierto y seguro el empeño o el ofrecimiento de las joyas.

Transcribe a continuación el acucioso historiador peninsular los versos y las estrofas con que los vates españoles han contribuido a difundir la leyenda, desde Lope de Vega, el duque de Rivas, don Ramón de Campoamor y don Antonio de Trueba, hasta otros poetas de más humilde nombre y significación.

Después de consignar que en más de una ocasión las joyas de la corona fueron empeñadas para satisfacer las necesidades de la hacienda. Fernández Duro es de opinión de que emientras no apa-

- Tradiciones infundados. Examen de las que se refieren al pendón morado de Castilla, las joyas de lsabel la Católico, las naves de Cortés, el salto de Alvarado. la Virgen de Lepanto, el estandarte de don Juan de Austria y otras. Madrid, 1888, págs. 360-61. 
rezcan testimonios fehacientes, la supuesta oferta de las joyas carece de fundamenlo históricos.

El prolesor don Eduardo Ibarra y Rodriguez, sostuvo también. con muy buenas razones, en su libro Don Fernando el Calólico y el descubrimiento de América. dado a la estampa en 1892. la tesis de que los fondos proporcionados a Colón para su primer viaje los facilitó Santangel. tomándolos del tesoro de Aragón. Aún cuando las páginas del volúmen del catedrático de Zaragoza están dedicadas a vindicar la memoria del Rey Calólico del cargo de hostilidad al insigne genovés, que le han formulado los historiadores de Colón, y alienta en ellas un pequeño espiritu regionalista, no se puede menos de reconocer la exactilud de las pruebas aducidas por el aulor. Los escritores conlemporáneos de Colón. los cronistas de Indias, y los historiadores Irving y Prescott, están de acuerdo en atribuir a Sanlangel una participación decisiva en la entrega de los fondos. Ibarra y Rodriguez, mediante el estudio de algunos documentos del siglo XV y de la organización de la Hacienda aragonesa, llega a una conclusión similar. EDe todas suertes, termina diciendo, sea un particular el prestamista, sea el Tesoro, lo cierto. lo innegable, lo incontrovertible. es que un aragonés dió los fondos necesarios y que de Aragón salieron: es por consiguiente, un título de gloria para nuestro reino. $e^{l}$ haber contribuido a la realización de la empresa, aportando entre otras cosas. los medios materiales para realizarla. •

Pero ha correspondido a otro historiador peninsular. investigador eruditísimo, don Manuel Serrano y Sanz. el mérilo señaladisimo de destruir en forma inequívoca la leyenda. En su volumen Origenes de la dominación española en América. dado a la estampa en Madrid en 1918. ha exhibido el fruto de su labor investigadora. No faltaban los elementos para rastrear la verdad. pero faltaban la dedicación y el valor moral para exponerla. Con el estudio de los documentos existentes en el Archivo de Prolocolos de Zaragoza, en el Archivo de la Corona de Aragón y en el del Real Patrimonio que se conserva en Bar-

- Obra citada. pág. 173. 
celona, pudo el historiador peninsular llegar a conclusiones que bien podemos considerar definitivas.

Ante todo. ¿quién era ese acaudalado Luis de Santangel que proporció el dinero para el primer viaje de que hablan los escritores conlemporáneos? Nada menos que un judio converso, que alcanzó altisima situación en la Corte de los Reyes católicos. Ya antes que Serrano y Sanz, un historiador norteamericano, Kayserling. habia señalado la importancia de la participación de los judios en la empresa de Colón * pero el escritor peninsular es quien ha podido delerminar con mayor precisión y acierto la extensión y caracteres de aquella participación. Para la investigación de esle punto ha prestado vivisima luz un libro curiosísimo, conocido con el nombre de Libro verde de Aragón. en el que se hacen detalladas genealogias de las familias aragonesas de ascendencia hebraica. El escándalo que produjo su publicación movió a Felipe IV, a instancias del Consejo de la Inquisición. a ordenar la confiscación de todos los ejemplares. lo que no fué obstáculo para que algunas copias manuscrilas de él se salvaran del acucioso celo de los inquisidores. Una copia de él, hallada por don José Amador de los Rios en la Bibliofeca Colombina de Sevilla, fué publicada por su hijo hace algunos lustros en la Revista de España, pero hay otra copia que se conserva en el Archivo Históricó Nacional de Madrid. ¿Si comparamos el lexto del Libro verde, escribe Serrano y Sanz. publicado por don Rodrigo Amador de los Ríos con el de otro manuscrito, también de fines del siglo XVI, que se conserva en el Archivo Histórico Nacional de Madrid, nótase que hay entre ambos grandisimas diferencias; el segundo es mucho más extenso. de tal modo que el capitulo referente a la familia de los Santangel contiene doble número de noticias que el primero: lo mismo sucede con otras genealogias, y adviértese tambiên que algunas afirmaciones rotundas del manuscrito de la Colombina, aparecen en forma dubitativa en el del Archivo Histórico. Todo esto prueba que

- Chistopher Columbus and the parlicipation of the Jews in the Spanish and Porfuguese discoveries. New York, 1907. 
La leyenda de las joyas de la reina Isabel

el Libro verde, una vez hecho público y puesto en manos de los curiosos, recibió numerosas adiciones, sin contar con otras que se le hicieron cuando aún se guardaba en el Archivo del Santo Oficio de Zaragoza. y por lanto. que tuvo una redacción progresiva, especialmente en el breve tiempo que rodó satisfaciendo la curiosidad y malevolencia de muchos.

Con los elementos mencionados ha podido, pues, el diligente historiador español, reconstituir el origen de la Tamilia de Santangel, que es netamente judaico. y cuyo apellido, antes de convertirse, era de Chinillo o Chiniello. Era esta una antigua familia de Aragón. cuyas primeras huellas es posible constatar ya en el siglo XIII, y que pronto prosperó en riquezas e influencia social. Ya en el siglo XV era la de los Santangel una familia preeminente, acaudalada y prestigiosa, habiendo llegado uno de sus miembros a obtener el cargo de obispo de Mallorca. Luis de Santangel. el amigo y profeclor de Colón. era hijo de otro judío del mismo nombre, quien a su vez descendia de Noé Chinillo, israelila de Calatayud. Fué tambiẻn la familia en cuestión víctima de las más feroces y ensañadas persecuciones de la Inquisición. en cuyas horcas y aulos de fe perecieron muchos de sus miembros. Casi todos los que han escrito acerca de Luis de Santangel, Escribano de ración, dice Serrano y Sanz, están conformes en decir que fué aragonés, afirmación del todo inexacta, ya que él mismo se llama nafural de la ciutat de Valencia, por lo que únicamente puede ser calificado de aragonés en el sentido de que descendia de una familia de judios aragoneses, convertidos al cristianismo al principio del siglo XV. - En 1481 obtuvo Santangel, de Fernando de Aragón. el cargo de Escribano de ración. ‘con todos los derechos honorificos y lucrativos de tal cargo, dice Serrano y Sanz, ni tan elevado como algunos han escrito, ni tan infimo como otros han afirmado.

Numerosas y complicadas eran las funciones del Escribano de ración. Su obligación principal consistia en llevar cuatro

- Obra cilada. pág. CII. 
libros. en el primero de los cuales debia registrar los nombramientos de los servidores del palacio real, y el sueldo de cada uno: en el segundo se hacia un inventario de las joyas, armas. vajilla, ropas, relablos, ornamentos y muebles del palacio: en el tercero se consignaban los gaslos diarios de la casa real, y en el cuarlo los albaranes o carlas de pago, de quitaciones o sueldos de los funcionarios anotados en el primero. Además de llevar los libros mencionados, el Escribano de ración anolaba los nombres de los que comían en palacio. En tiempos de guerra las atribuciones de dicho funcionario se ampliaban: debia dar de comer y beber a jeles y soldados a cuenta de sus salarios; le correspondia nombrar los jineles y peones que debian escoltar y servir de centinelas al monarca; y por último le compelía pagar el sueldo, por trimestres, a los sirvientes de palacio.

En 1486 conoció Santangel a Colón en Córdoba. •¿Qué motivos originaron. escribe don Manuel Serrano y Sanz. las relaciones cordiales que hubo desde entonces entre Colón y Santangel? ¿Acaso el proceder ambos del judaismo? Mientras con documentos auténticos, no raspados ni añadidos, como casi todos los alegados hasla ahora para demostrar que Colón descendia de judios, no se pruebe que en las venas de éste corria sangre israelita, será infundado y lemerario dar semejante explicación a un hecho que, siquiera provisionalmente, hemos de atribuir a causas distintas. Y. dejando a un lado estas cavilaciones, buenas únicamente para forjar una novela, es lo cierto que entre Colón y Santangel hubo las afinidades psicológicas necesarias para que entre ambos naciese amistad verdadera y sólida. que luego se consolidó andando los años, ¿Quién sabe si Santangel, que, como todos los de su raza, tenía especial aptitud para ver de lejos los negocios provechosos, no adivinó. por intuición de buen mercader. las cuantiosas riquezas que podian traerse de las tierras a donde quería ir Colón, y aún se regocijaba con el pensamiento de asociarse en tales empresas al nuevo amigo, que lantas grandezas promelia con sus descubrimienlos? El préslamo que años más adelante hizo para el primer viaje de Colón, y el haber conjeturas no despreciables 
de que acaso anticipó a éste una parte de la suma con que habia de contribuir a los gastos. hacen que tal hipótesis no carezca por completo de fundamentos.

Ya el mismo don Fernando Colón afirmaba que Luis de Santangel había facilitado el dinero para el primer viaje, afirmación que acogió el padre Las Casas. Este hecho. en el cual han estado de acuerdo los historiadores primitivos de Indias. como hemos visto. ha dado lugar a no pocas polémicas. y los cronistas aragoneses de los siglos XVI y XVII han gastado grandes esfuerzos en probar que el dinero salió de las arcas del Tesoro de Aragón. Todas las invenciones de los cronistas aragoneses, escribe Serrano y Sanz, para demostrar que las Indias fueron descubierlas a expensas del Tesoro de Aragón. fundábanse principalmente en el hecho, erróneo a más no poder, de ser natural de Calatayud el Escribano de ración Luis de Santangel, y que solia residir en dicha ciudad, donde alguna vez lo visitó el Rey Católico hallándose éste en grave siluación económica. De haber sabido que Santangel. aunque descendiente de familia bilbilitana, era y él se decia natural de la ciufat de Valencia, los mencionados cronistas no se habrian esforzado en la probanza de las lesis hislóricas que unos inventaron y otros acogieron y ampliaron, creyendo que realizaban una labor digna de alabanza por patriótica, ya que no podia serlo por veridica, y concienzuda, *

Sin embargo, se conservan en el Archivo de Simancas los documentos que prueban que Santangel facilitó los 1.140.000 maravedis que fueron necesarios para el primer viaje de Colón. documentos que nuestro autor transcribe integros en su eruditisimo estudio. De ellos se desprende que Santangel tenía una especie de sociedad con Francisco Pinelo para recaudar lo que produjese la Hermandad en Castilla y Galicia, que la cantidad indicada salió de fondos comunes, aunque la entregó únicamente Santangel. Las célebres Hermandades cuyo origen se remonla a la Edad Media, sufrieron una transformación fundamenlal en

- Obra cilada, pág. CXXIX. 
la época de los Reyes Calólicos, y poco después se refundieron en la Santa Hermandad. No era ésta un organismo autónomo. ni aún para la recaudación de los tribulos. los que eran cobrados por medio de arriendos y delegaciones; de aquí que Pinelo y Santangel se encargaran de la recaudación de las rentas de la Hermandad en 1490, durante un trienio. Uno de dichos documentos deja constancia de que, no habiendo cobrado el Escribano de ración el préstamo que habia hecho. se le admitia como descuento de lo que él y Pinelo habian cobrado de la Hermandad. .En lo del 1.140.000 maravedis que paresce que prestó el Escribano de ración, dice el documento, para el despacho del Almirante de las Indias, sobre que a Vuestras Altezas escrivi que hasta ver las otras quentas de Luys de Santangel no ge lo pasavamos en quenta.....

\section{IV}

La leyenda queda destruída. Pero no por eso pierde ella los seductores contornos del más bello simbolo, revelador de la preclara acción de la reina. Aunque la acción de Isabel fuera menos heroica e independiente de la de su marido de lo que algunos biógrafos entusiastas gustan de representar. escribe un historiador desapasionado, es cierto que sin ella no hubiera Fernando favorecido la expedición. Atendiendo al conjunto de las circunstancias y a su carácler. no es seguro el censurarle excepto en lo que se referia a consentir condiciones que sabía claramente no podria cumplir. Pero el idealismo de Isabel. en este caso, era más cuerdo que la prudencia práctica de Fernando. por lo que toca a los resultados que inmedialamente se siguieron, y a Isabel la $\mathrm{Ca}$ tólica debe atribuirse la gloria de haber ayudado a Colón. más bien que a Fernando, que, con resislencia, se dejó persuadir. "

Desterremos, pues, de los libros y de la cátedra la vieja leyenda, ya que, si es penoso desechar una poética ficción. es más noble rendir Iributo a la perdurable eternidad de la verdad.

- Obra cifada, pág. CXXXIV.

* Martin Hume, Reinas de la España antigua, pág. 89. 